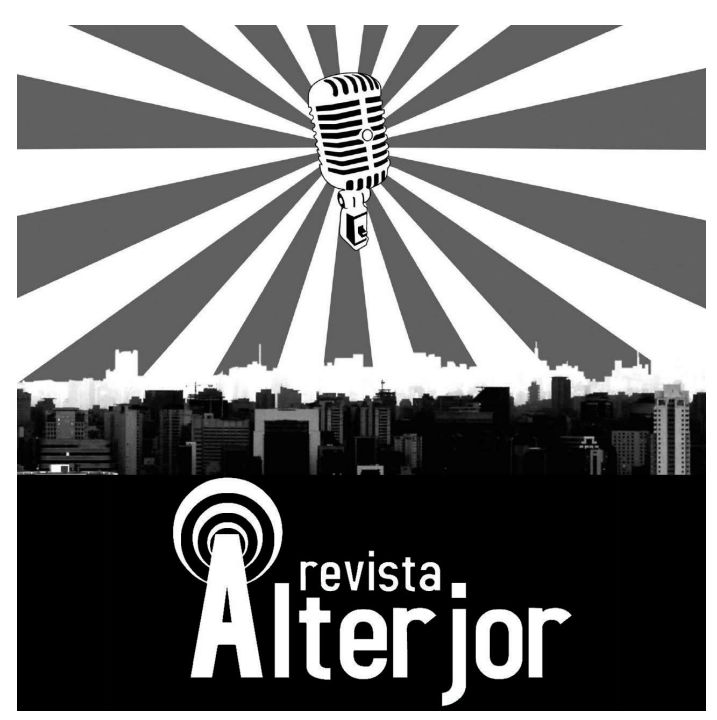

RELATÓRIO DE PESQUISA

\title{
A PREPARAÇÃO DO ALUNO PARA O MERCADO DE TRABALHO
}

\author{
Ana Carolina dos Santos da Silva Kauer ${ }^{1}$
}

RESUMO: O presente trabalho busca elaborar atividades, ideias que impulsione o jovem para o mercado de trabalho e se encontram perdidos frente as escolhas profissionais, ajudando também as famílias e a escola para saber como lidar neste processo de mudança, e como podem contribuir frente a esta questão, o trabalho irá também destacar a importância da participação da família e comunidade neste processo. Mas para isto é necessário conhecer quais aspectos influentes que afetam na escolha profissional em relação a um curso superior ou técnico por parte dos alunos, principalmente do Ensino Médio, e uma boa fundamentação a respeito das opções da formação continuada.

PALAVRAS-CHAVE: Educação. Mercado de trabalho. Formação continuada..

ABSTRACT: The present work seeks to develop activities, ideas that encourage young people to enter the labor market and find themselves lost in professional choices, also helping families and schools to know how to deal with this process of change, and how they can contribute to this issue, the work will also highlight the importance of family and community participation in this process. But for this it is necessary to know which influential aspects affect the professional choice in relation to a higher or technical course by students, especially in high school, and a good foundation regarding the options for continuing education.

KEYWORDS: Education. Job Market. Continuing education.

\footnotetext{
Licenciada em Pedagogia pela Universidade Anhanguera-Uniderp, polo Novo Hamburgo. E-mail: anacarolina.as49@gmail.com
}

\section{Revista ALTERJOR}

Grupo de Estudos Alterjor: Jornalismo Popular e Alternativo (ECA-USP)

Ano 11 - Volume 02 - Edição 24 - Julho-Dezembro de 2021

Av. Professor Lúcio Martins Rodrigues, 443, Cidade Universitária, São Paulo, CEP: 05508-020 


\section{Introdução}

Nos dias de hoje podemos verificar o alto o percentual de indecisos em relação às opções de formação para ensino superior, ou mesmo técnico, que estudam no Colégio do Futuro da cidade de Santa Maria, no Rio Grande do Sul. O seguinte trabalho apresentará o projeto "Construindo meu projeto de vida" que consiste em trazer ao aluno a importância da qualificação para o mercado de trabalho.

O presente trabalho busca elaborar atividades, ideias que impulsione o jovem para o mercado de trabalho e se encontram perdidos frente as escolhas profissionais, ajudando também as famílias e a escola para saber como lidar neste processo de mudança, e como podem contribuir frente a esta questão, o trabalho irá também destacar a importância da participação da família e comunidade neste processo. Mas para isto é necessário conhecer quais aspectos influentes que afetam na escolha profissional em relação a um curso superior ou técnico por parte dos alunos, principalmente do Ensino Médio, e uma boa fundamentação a respeito das opções da formação continuada.

O projeto terá duração de um ano e durante esse o período os alunos terão a oportunidade de conhecer diversas profissões, eles terão atividades que serão implementadas nos seus estudos durante o ano letivo, sendo elas palestras com profissionais de diversas áreas, e com coordenador de uma faculdade, pesquisando sobre currículos, elaborando trabalhos, questionários avaliativos, e entrevistas coletivas. O trabalho procura auxiliar os alunos, para que eles desenvolvam seu autoconhecimento, direcionando-se melhor para sua futura carreira profissional, para que eles possam estar adquirindo habilidades e competências para sua carreira profissional, enfim, estando preparado para o mercado de trabalho.

Os elementos aqui apresentados resultam de pesquisas com alunos, pais de alunos e professores do terceiro ano do Ensino Médio do Colégio do Futuro citado e de estudos bibliográficos voltados ao tema aqui tratado.

O trabalho discorre sobre a posição que os jovens se encontram em relação á difícil escolha profissional, tornando-se importante refletir sobre esta situação como

\section{Revista ALTERJOR}

Grupo de Estudos Alterjor: Jornalismo Popular e Alternativo (ECA-USP)

Ano 11 - Volume 02 - Edição 24 - Julho-Dezembro de 2021 Av. Professor Lúcio Martins Rodrigues, 443, Cidade Universitária, São Paulo, CEP: 05508-020 


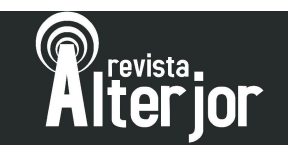

forma de ajudar na orientação destes, neste processo, principalmente nas séries finais do Ensino Médio, apresentando o valor de se fazer uma profunda análise do assunto, o porquê de se desenvolver planos, técnicas que possam ajudar os alunos a ter uma escolha mais ampla e definida de sua carreira profissional, estando ele apto e qualificado para o mercado de trabalho, assim também contribuindo com a comunidade escolar, e envolvendo as famílias de alunos neste projeto, sendo ele contributivo e participativo para o beneficiamento coletivo entre ambos.

\section{Perfil da Escola}

O colégio Futuro, foi criado em 26 de março de 1990, com o objetivo de formar cidadãos para o mercado de trabalho. A instituição possui o nível da educação básica localizada em área urbana, na cidade de Santa Maria, no estado do Rio Grande do Sul, com nível de ensino de educação básica, ela possui três turnos, o matutino, vespertino e noturno, as aulas acontecem de segunda a sexta, em geral procede de bons indicadores de desempenho nas avaliações, conta com um conjunto de funcionários, entres eles, cozinheiros, faxineiros, segurança, supervisor pedagógico, orientador educacional, inspetor, secretária, professores, bibliotecário, coordenador pedagógico e diretor.

A infraestrutura da escola é composta de serviços básicos, biblioteca, museus, dois banheiros masculino e feminino cada qual compõem três compartimentos separados, quadra esportiva, laboratório de informática e de ciência e área do lanche. Conta com recursos e equipamentos eletrônicos e portáteis para auxiliar num ensino de qualidade. $\mathrm{O}$ estabelecimento conta com diversos materiais didáticos desde a parte eletrônica ao manual para auxiliar os professores e alunos na educação, é oferecida uma agenda por aluno para recados, agendar provas e trabalhos, um computador por aluno quando forem na sala de informática e um tablet, que ficará na escola e os alunos irão receber ao chegar à sala de aula, livros didáticos para ajudar no seu ensino. A escola contém ao total trinta salas de ensino e lazer.

Corpo docente da escola é composto por trinta professores, a maioria iniciou sua atuação no Colégio entre 1978 a 2007. Todos os profissionais são formados com ensino

\section{Revista ALTERJOR}

Grupo de Estudos Alterjor: Jornalismo Popular e Alternativo (ECA-USP)

Ano 11 - Volume 02 - Edição 24 - Julho-Dezembro de 2021 Av. Professor Lúcio Martins Rodrigues, 443, Cidade Universitária, São Paulo, CEP: 05508-020 


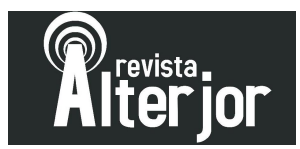

superior na área que atuam, cumprem a carga horária de 40 horas semanais. Em relação ao corpo discente ao todo se dá em torno de quinhentos e trinta alunos, compreendendo vinte e seis turmas.

A escola não possui conflito de gênero, a diversidades entre os alunos são respeitadas, a maioria dos alunos são de classe média. A escola possui alguns alunos com histórico de repetências em modalidade fundamental e médio, possuindo também alunos em turno noturno onde parte deles trabalham, moram com as famílias, cuja renda varia entre cinco e dez salários mínimos. 56\% participam de instituições religiosas. Não estão inseridos em organizações sociais e afirmam que gostam de ler, mas também que ocupam seu tempo livre, prioritariamente, assistindo TV e navegando pela internet. Segundo a pesquisa realizada na escola, quanto aos que pretendem fazer após a conclusão do Ensino Médio, as respostas dividem-se em trabalhar e continuar os estudos em nível superior.

\section{Justificativa}

A elaboração do presente projeto surgiu a partir do diagnóstico realizado no Colégio Futuro, onde pude perceber o intenso números de jovens da nossa atualidade que não sabem designar o que realmente querem para seu futuro e até mesmo as suas escolhas impulsivas. Em razão do índice elevado de número de alunos que não estão preparados para a entrada no mercado de trabalho, para atender as demandas que ele exige nos dias atuais, o projeto torna-se relevante para haver mudanças neste número. De acordo com a publicação feita no portal CMC pelo aprendiz do conhecimento humano, Sakaizen Sakurai afirma que:

São pessoas que não sabem o que fazer da vida, qual profissão escolher e continuam vagueando na incerteza rumo a lugar nenhum. São como as naus sem rumo. Não têm noção de onde estão, nem para onde querem ir e quando chegam em algum lugar, não têm ideia de onde chegaram. A cada dia aumenta o número de indecisos e eternamente insatisfeitos que não sabem o que querem da vida, a maioria constituída por jovens perdidos numa longa noite escura. (Sakaizen Sakurai. Eu não sei o que quero da vida. Em: http://www.portalcmc.com.br/eu-nao-sei-o-quequero-da-vida/\#. Acesso em: 22 março 2017.)

\section{Revista ALTERJOR}

Grupo de Estudos Alterjor: Jornalismo Popular e Alternativo (ECA-USP)

Ano 11 - Volume 02 - Edição 24 - Julho-Dezembro de 2021 Av. Professor Lúcio Martins Rodrigues, 443, Cidade Universitária, São Paulo, CEP: 05508-020 


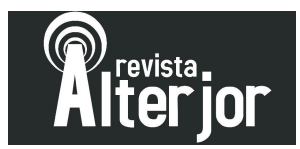

A proposta do trabalho vem com finalidades de mudanças em relação a estes problemas, propõem se estimular os jovens na tomada de decisões corretas para suas aptidões futuras, o jovem precisa se conhecer para que obtenha sucesso na hora da escolha de sua carreira profissional, é necessário que ele se localize, reflita no seus planos e objetivos traçados para seu futuro, para que se sinta realizado e satisfeito na sua escolha profissional, que possa buscar atingir as metas que o mercado de trabalho propõe, estando ele pronto, diplomado para atender as exigências que o mercado exige, no decorrer do tempo o mercado de trabalho se atualizou muito, sofreu diversas mudanças influenciadas principalmente de tecnologias em seu âmbito profissional, de acordo com o autor Robsom Castro comenta estas modificações que o ramo vem sofrendo:

\footnotetext{
O mercado de trabalho, hoje se encontra mais competitivo do que nunca. Profissões de vários tipos surgem enquanto outras desaparecem. Essas novas profissões que surgem exigem um grau cada vez maior de especialização, pois estão diretamente ligados a áreas de extrema tecnologia. Isso além de tornar o mercado mais competitivo, em virtude de ser uma área cada vez mais promissora, $[\ldots]$.
}

(CASTRO, 2008, p. 2)

O projeto tem como objetivo melhorar o ensino e a educação do aluno, conta como instrumento propostas de atividades para efetivar essas ideias, modificações de melhorias na comunidade escolar. As mudanças que a sociedade passou com o decorrer do tempo, fizeram que as necessidades se ampliassem, como na educação, no trabalho e principalmente no que tange a tecnologia e o conhecimento, com tantas mudanças o mercado de trabalho exigiu novo perfis profissionais habilitados para ele, por isto o trabalho busca metas eficazes para auxiliar não somente alunos como pais e professores neste processo de formação profissional e de cidadão, a escola, o município, e o estado tem o dever de ajudar neste processo de desenvolvimento, sendo que o papel da escola é atender as necessidades dos educandos exercendo sua função social, formando cidadãos éticos e dignos, cumprindo assim, com os valores da sociedade em que vivem e o estado precisa oferecer condições para que ocorra articulações entre a escola e o mundo do trabalho, como instrumento de promoção da cidadania, incorporando conhecimentos,

\section{Revista ALTERJOR}

Grupo de Estudos Alterjor: Jornalismo Popular e Alternativo (ECA-USP)

Ano 11 - Volume 02 - Edição 24 - Julho-Dezembro de 2021 Av. Professor Lúcio Martins Rodrigues, 443, Cidade Universitária, São Paulo, CEP: 05508-020 


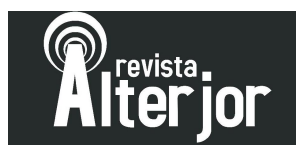

habilidades, técnicas, novas formas de solidariedade social, e vínculos dos trabalhos, às lutas sociais pela democratização do Estado.

O que me levou a desenvolver este projeto na escola, foi pelo fato de perceber que havia muitas dificuldades entre os alunos do Colégio do Futuro, em relação a escolha do caminho profissional, notei que esta indecisão por parte dos alunos, se associada a vários motivos como, influência familiar, o medo, frustração, remuneração e instabilidade profissional, e satisfação do ambiente profissional, observei o grande desafio dos pais, e professores em auxiliar eles neste processo, os professores ficam perplexos diante de tantos alunos sem planos de carreira, a preocupação é coletiva, pais desorientados frente ao assunto tratado, sem saber o que fazer e como agir diante deste fato, o trabalho busca orientá-los e encontrar uma solução minimizadora para esta questão social.

O trabalho busca atingir o beneficiamento como num todo, onde irá fazer com que os jovens, famílias, comunidade, empresas se beneficiem, podendo repercutir no desenvolvimento político, econômico social do país, o projeto em si requer melhoras no processo educacional e de desenvolvimento do jovem estudante, para sua capacitação profissional e pessoal, porém as reformas só serão possíveis quando houver uma ajuda coletiva, procedente de participação por parte da comunidade escolar, a família, sociedade, estado e governo, a participação possibilita o envolvimento de todos os integrantes da escola no processo de tomada de decisões e no funcionamento da organização escolar, além disso, a participação proporciona conhecer os objetivos e as metas da escola, sua estrutura e suas relações com a comunidade. De acordo com as educadoras da área Bhering e Siraj-Blatchford comentam que a participação dos pais no cotidiano escolar dos filhos é um fator determinante para o desempenho do aluno na escola, tornando a família e a instituição importante no processo ensino aprendizagem, elas afirmam que:

O envolvimento dos pais não só contribui com todo o processo escolar (tudo que isso implica) como também contribui para uma melhoria dos ambientes familiares (no sentido de provocar uma maior compreensão do processo de crescimento e, portanto, da aprendizagem das Crianças) eventualmente poderá influência influenciado positivamente o curso do desenvolvimento das crianças como o rendimento escolar. (Bhering,

\section{Revista ALTERJOR}

Grupo de Estudos Alterjor: Jornalismo Popular e Alternativo (ECA-USP)

Ano 11 - Volume 02 - Edição 24 - Julho-Dezembro de 2021 Av. Professor Lúcio Martins Rodrigues, 443, Cidade Universitária, São Paulo, CEP: 05508-020 


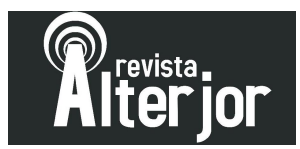

Eliana; Siraj-blatchford, Iram. A relação escola-pais: um modelo de trocas e colaboração. Em:

http://www.scielo.br/pdf/cp/n106/n106a09.pdf. Acesso em: 03 abril 2017).

A colégio do futuro tem se refletido nos discentes como um referencial de aprendizagem formativa pessoal e social, ela vem trazendo aspectos essências para a construção da identidade, autonomia, educação de qualidade e competências dos indivíduos, nos quais estão inseridos nos princípios da Lei de Diretrizes e Base da Educação Nacional, entre eles os mais relevantes para o ensino de qualidade, estão o Projeto Político Pedagógico (PPP), docentes qualificados para a pratica pedagógica, equipe pedagógica qualificada, boa gestão democrática, avaliações adequadas, infraestrutura capacitada, um bom ambiente físico e educativo, formação continua e condições de trabalho aos profissionais. O colégio futuro é aprovado pelo MEC (Ministério da Educação). O mesmo foi projetado com capacidade para oferecer conforto, acessibilidade melhor atendimento para professores (docentes) e alunos (discentes) tanto com alguém tipo de deficiência ou os com melhores habilidades. Esta escola é considerada diferenciada, pois foi projetada com qualidade, apta a fornecer competência e habilidade para seus alunos inclusivos ou não.

\section{Objetivos Gerais}

Aplicar um projeto colaborativo, participativo e interativo-social, auxiliando na decisão e na qualificação profissional, impulsionando ele a refletir sobre futuro profissional e preparando-o para o mercado de trabalho.

\section{Objetivos Específicos}

Auxiliar o aluno na sua tomada de decisão rumo a profissão.

Provocar nos alunos a iniciativa de pensarem em seu futuro profissional.

Promover interação da comunidade para melhor auxiliar o educando ao ingresso no mercado de trabalho.

\section{Revista ALTERJOR}

Grupo de Estudos Alterjor: Jornalismo Popular e Alternativo (ECA-USP)

Ano 11 - Volume 02 - Edição 24 - Julho-Dezembro de 2021 Av. Professor Lúcio Martins Rodrigues, 443, Cidade Universitária, São Paulo, CEP: 05508-020 


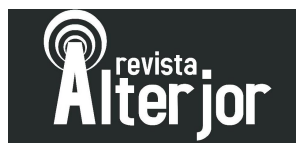

Criar metas e planos coletivos para auxiliar o educando no seu desenvolvimento social e cultural.

Criar atividades que possam envolver o aluno, família e professores.

Estimular o jovem a pensar na sua carreira profissional.

\section{Metodologia}

O projeto "Construindo meu projeto de vida" trata-se de um método de estudo experimental, onde eles irão executar as atividades elaboradas. A primeira etapa da implementação do projeto, iniciara com apresentação da proposta para a direção da escola, equipe pedagógica, professores, alunos e pais, ocorrera no Colégio Futuro, em Santa Maria, no ano de 2001, na segunda semana do mês de fevereiro e na primeira semana do mês março, com os 200 alunos do Ensino Médio.

Primeiramente ocorrerá entre a segunda semana o mês de março a última semana do mês de abril, os educandos serão convidados a irem na instituição de Santa Maria para assistirem a palestra do coordenador administrativo, especialista formado em administração empresarial e financeira, Joaquim Fonseca. Onde ele irá discorrer sobre orientação profissional, em seguida os alunos irão retornar a sua escola e irão para suas salas formar duplas, para executar um trabalho sobre a palestra assistida na faculdade onde foram, terão que fazer uma apresentação sobre o assunto, poderão fazer uso dos computadores da escola, como também livros, podendo apresentar na forma que acharem melhor, ou seja, em slides, data show, maquetes etc. Os materiais de uso pra exposição do trabalho podem ser o uso da tecnologia, quadros, figuras, colagens, recortes.

Na terceira parte da implementação que ocorrera entre a primeira semana do mês de maio terceira semana de junho, os educandos em sala de aula individualmente deverão desenvolver perguntas, um prévio questionário, onde o professor irá avaliá-lo nesta atividade (elaboração de questões), que em seguida os alunos usarão este questionário elaborado para interagir com alguns palestrantes (de várias profissões) de diversas empresas de Santa Maria, que virão na escola, para dialogar e debater com os alunos sobre

\section{Revista ALTERJOR}

Grupo de Estudos Alterjor: Jornalismo Popular e Alternativo (ECA-USP)

Ano 11 - Volume 02 - Edição 24 - Julho-Dezembro de 2021 Av. Professor Lúcio Martins Rodrigues, 443, Cidade Universitária, São Paulo, CEP: 05508-020 


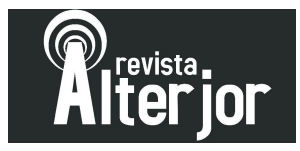

os seus cotidianos profissionais e tirar dúvidas sobre as referidas profissões. Cada palestrante deverá falar por trinta minutos e, em seguida, os alunos poderão realizar suas perguntas sobre os prós e contras de cada profissão utilizando seu questionário.

$\mathrm{Na}$ quarta parte da ação, serão feitas entrevistas coletivas farão entrevistas com familiares, e pessoas do seu meio social, os alunos irão formular perguntas relacionadas a vida profissional dos entrevistados, o porquê resolveu optar por tal emprego e como chegou até ele, entre outras perguntas sobre o assunto, depois farão em sala de aula uma pequena análise crítica, reflexiva sobre suas entrevistas, os resultados destas atividades deverá ser apresentada em sala de aula para seus colegas em forma de Power Point onde eles irão argumentar, falar sobre o assunto, dizendo que aprendeu, o professor poderá avaliar esta atividade na forma de um trabalho. Os recursos que eles utilizarão são cadernos de anotações, computador sua própria tecnologia (celular, tablet, câmera etc.), para fazer pequenas filmagens ou áudios, para gravações de conversas. Esta implementação deve ocorrer quarta semana de junho e a última semana do mês de julho.

Na última etapa da implementação que ocorrerá entre o início do mês de agosto a terceira semana do mês de setembro, os alunos pesquisar sobre currículos, o que são estes documentos, da onde surgiu, qual sua finalidade, aonde e quando é utilizado, enfim, tudo sobre o currículo, a pesquisa pode ser feita em todos os lugares dede internet a livros. Depois de pesquisar os alunos, irão elaborar um currículo, mas para redigir o documento solicitado ele fara o uso do Word, e em seguida deverá entrega-lo para o seu professor que irá avaliar esta atividade e corrigi-la com a turma.

$\mathrm{Na}$ quarta semana do mês de setembro e o fim do mês de outubro deve ocorrer os resultados das implementações estiveram satisfatórias tantos para alunos como para os professores, para a coordenação escolar, e para as famílias dos educandos. A proposta beneficiou como num todo. Obteve-se uma melhor orientação para os alunos, os assuntos ficaram mais explicados. Possibilitou uma noção melhor sobre o ingresso para o mercado de trabalho, e a vida profissional em relação a suas escolhas ficaram mais esclarecidas. Com estas atividades os alunos se mostraram interessados e com muita expectativa em relação ao ramo empresarial, estes exercícios também trouxe elementos que

\section{Revista ALTERJOR}

Grupo de Estudos Alterjor: Jornalismo Popular e Alternativo (ECA-USP)

Ano 11 - Volume 02 - Edição 24 - Julho-Dezembro de 2021 Av. Professor Lúcio Martins Rodrigues, 443, Cidade Universitária, São Paulo, CEP: 05508-020 


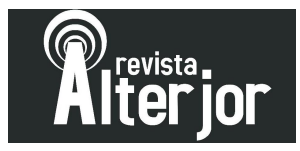

possibilitaram o clareamento, significados aos educadores e também técnicas de ação que serviram como uma referência básica no processo de orientação pedagógica dos alunos e também para que eles possam auxiliar melhor seus alunos em relação as opções de profissões.

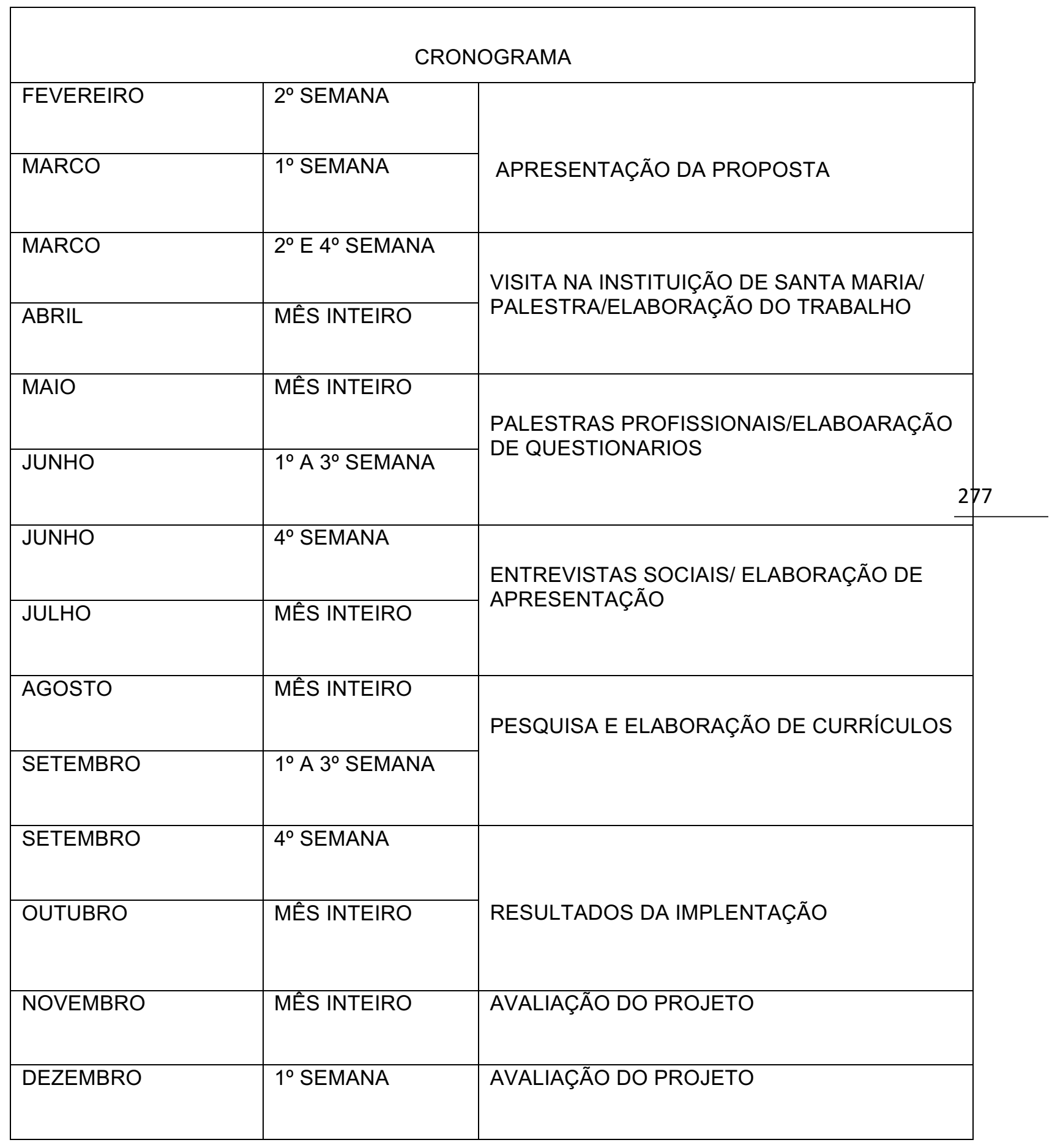

\section{Revista ALTERJOR}

Grupo de Estudos Alterjor: Jornalismo Popular e Alternativo (ECA-USP)

Ano 11 - Volume 02 - Edição 24 - Julho-Dezembro de 2021 


\section{Antiejor}

Entre os meses de novembro e dezembro haverá a avaliação do projeto, ao término do projeto, os alunos deverão estar mais orientados frente ao assunto exposto no trabalho.

A partir da realização deste projeto, é possível apresentar algumas reflexões sobre o desenvolvimento deste trabalho, sua validade e sugestões para o aprimoramento deste projeto educativo para a comunidade escolar.

\section{Avaliação}

Ao término deste projeto a avaliação será dialogada, argumentada, debatida, coletivamente, as ações neste projeto poderá ser confrontada como também concordada, fazendo-se uma reflexão sobre o mesmo. A avaliação do projeto em si, será na coordenadoria de ensino, juntamente com a secretaria de educação e a comunidade escolar, avaliar este projeto em torno de parâmetros curriculares, e normas da Lei de Diretrizes de Base da Educação, o modo que os agentes irão avaliar se baseia em cima da elaboração dos planos desenvolvidos no projeto, metas, estratégias para mudanças nas ações educativas em relação ao tema aqui exposto. Será analisado os fatos a serem colocados na proposta para o ensino, os avaliadores farão o uso da profunda leitura no projeto podendo descrever os erros, acertos verificando as soluções para a problemática em torno do trabalho a ser desenvolvidos com os alunos do Ensino Médio. Através do projeto executado, será feito um levantamento de benefícios para a comunidade escolar, deverá ocorrer critérios e debates com a equipe avaliadora, levantando os conceitos do projeto em pauta, exercendo uma análise reflexiva, e critica-opinativa, descrevendo prós e contras do projeto. Os resultados das implementações só estarão satisfatórias se atendidos todos os objetivos que o projeto propôs para realização do mesmo. Através das atividades envolvidas no projeto, só será considerado suficiente se atingir 50\% dos efeitos que o trabalho produziu.

Alguns instrumentos utilizados para a avaliação do projeto serão baseados em critérios que estão especificados por tópicos, dentre ele estão:

- Estar orientados para suas escolha profissionais, sabendo identificar suas aptidões;

\section{Revista ALTERJOR}

Grupo de Estudos Alterjor: Jornalismo Popular e Alternativo (ECA-USP)

Ano 11 - Volume 02 - Edição 24 - Julho-Dezembro de 2021 Av. Professor Lúcio Martins Rodrigues, 443, Cidade Universitária, São Paulo, CEP: 05508-020 


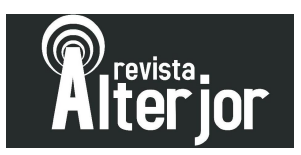

- Estar preparado e qualificado para o mercado de trabalho;

- Ter consciência do curso profissionalizante, que se quer realizar, seja ele um curso técnico ou superior, assim também conhecendo diversas áreas de profissões;

- Conhecer suas habilidades, interesses, e suas qualidades pessoais (autoconhecimento pessoal), designando assim o que ele quer para seu futuro profissional;

- Saber planejar sua carreira, que saiba técnicas, estratégias para seu sucesso profissional;

- Elaborar planos de carreira, para que ele possa distinguir, conhecer, saber, avaliar melhor sobre o curso que executará para sua carreira profissionalizante;

- Saber o que é o mercado de trabalho como ele tem reflete para a vida profissional

\section{Conclusão}

Diante dos argumentos apresentados acima, o trabalho aborda o assunto relacionado aos jovens frente a escolha de sua carreira profissional, de como ele se encontra diante à indecisão da escolha de sua profissão, e como os integrantes da escola e as famílias podem participar e auxiliar na vida destes alunos em relação a este tema. Portanto o trabalho elabora atividades, planos que possam contribuir no impulsionamento do jovem para o mercado de trabalho, possibilitando sua preparação e qualificação profissional, auxiliando nas suas escolhas profissionais dando um direcionamento para seu futuro profissional.

Resume-se que a solução deste problema, em relação as mudanças nestes quadros não estão somente na elaboração de projeto, mas também na interatividade como um todo, ou seja, deve haver uma ajuda mutua por parte da família, escola, e comunidade, possibilitando a melhora do ensino aprendizagem e auxiliando os educandos para a vida profissional social, dentro da Lei de Diretrizes e Bases da Educação e normas de

\section{Revista ALTERJOR}

Grupo de Estudos Alterjor: Jornalismo Popular e Alternativo (ECA-USP)

Ano 11 - Volume 02 - Edição 24 - Julho-Dezembro de 2021 Av. Professor Lúcio Martins Rodrigues, 443, Cidade Universitária, São Paulo, CEP: 05508-020 


\section{Preiejer}

Parâmetros curriculares de Educação. Assim, este trabalho apresenta algumas reflexões sobre estratégias, práticas de ações, medidas e ideias de intervenção, para trabalhar este momento de indecisão destes alunos auxiliando-os na escolha profissional mais adequada, e também para que os professores, direção da escola, toda a equipe pedagógica e comunidade, que possam atuar de forma a colaborar com seus alunos na perspectiva de auxílio nesta escolha.

Além disso, também permitiu uma pesquisa de campo para obter dados mais consistentes sobre as etapas do processo, fazendo com que eu buscasse informações em vários lugares tais como entrevistas com alunos, pais, professores, coordenador pedagógico e diretor, pesquisa bibliográfica e informática. Por meio deste trabalho pude constatar que há formas de intervir positivamente neste processo e também de aplicar concretamente tais ações na prática docente. Conheci e compreendi a situação problemática que os jovens se encontram, e como as famílias e a escolas se deparam com esta questões que acabam por envolver toda a comunidade, mas também contemplei as soluções que pode advir para estas dificuldades.

Este trabalho foi muito importante para meu conhecimento, o aprofundamento deste tema me possibilitou, obter informações importantes sobre o tema tratado, trazendo para mim dados que são de suma importância para minha formação profissional pois pode compor minha habilidade, capacidade e competência em meu estudo formativo, proporcionado aptidão na minha vida profissional e com certeza me auxiliando na vida social.

\section{Considerações Finais}

O desenvolvimento do presente estudo possibilitou uma análise de como o projeto em si pode auxiliar na vida social do aluno, e qual influência da família, da escola e a sociedade exerce em relação ao jovem na escolha da profissão. O presente projeto tem condições de contribuir significativamente para auxiliar o aluno na suas escolhas profissionais, ajuda-los a estarem mais decididos nas suas aptidões, dando uma orientação

\section{Revista ALTERJOR}

Grupo de Estudos Alterjor: Jornalismo Popular e Alternativo (ECA-USP)

Ano 11 - Volume 02 - Edição 24 - Julho-Dezembro de 2021 Av. Professor Lúcio Martins Rodrigues, 443, Cidade Universitária, São Paulo, CEP: 05508-020 


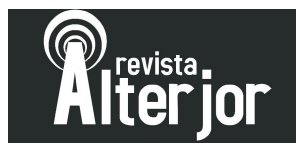

vocacional para eles, impulsionando-os a refletir sobre o mercado de trabalho, de forma a desenvolver neles as competências e habilidades voltadas para a carreira profissional.

Para ocorrer mudanças na escola sabemos que as alterações dependem de um compromisso coletivo dos próprios alunos, professores, gestores, pais e comunidade em geral, além disso a inclusão de programas são importantes para o excelente desenvolvimento educativo escolar, estas ações tem como objetivo procurar a melhor forma de atender estes alunos e os demais, buscando sempre o respeito, a igualdade de direitos e o melhor aproveitamento de ensino para todos.

O projeto em si mostrou-se considerável e satisfatório, sem dificuldades para implementar as ações, sendo que cada atividade elaborada foi pensada, analisada, e criteriosamente avaliada pelos agentes responsáveis. O projeto Construindo meu Projeto de Vida causou impacto na comunidade escolar, durante a socialização dos projetos pelos alunos, evidenciado nos comentários de pais, do corpo docente e do corpo discente da escola, contudo atendendo as expectativas esperadas. Este trabalho culminou em resultados significativo. Foi especialmente gratificante vê-lo contemplado no projeto político pedagógico da escola.

Com o elaborar deste trabalho conhecemos mais sobre a entrada do jovem para o mercado de trabalho, sobre o futuro profissional o que suas escolhas rementem ao longo da vida, ao passo do trabalho deu para reconhecer as dificuldades dos alunos em relação as suas decisões, e observei o modo de como o aluno se porta diante estas questões. $\mathrm{O}$ projeto buscou auxiliar de forma colaborativa, não somente alunos, como pais, professores, coordenador pedagógico, e todos que estão inseridos na rede escolar.

A proposta do trabalho "Construindo meu Projeto de Vida" favorece o desenvolvimento de um processo dialético de construção de conhecimento, capaz de romper com os paradigmas tradicionais e disciplinares da escola, ele se mostra muito importante para o ensino e para aprendizagem dos alunos, diante dos resultados do projeto percebe-se o quanto ele pode ser importante no desenvolvimento e aprendizado dos alunos, e não só dos que portam alguma deficiência, mas também os demais, que a partir do projeto elaborado podem conhecer e experimentar outras formas de aprender. Porém,

\section{Revista ALTERJOR}

Grupo de Estudos Alterjor: Jornalismo Popular e Alternativo (ECA-USP)

Ano 11 - Volume 02 - Edição 24 - Julho-Dezembro de 2021 Av. Professor Lúcio Martins Rodrigues, 443, Cidade Universitária, São Paulo, CEP: 05508-020 


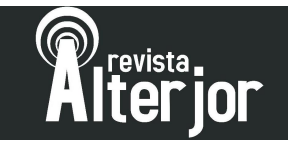

para isso, sabemos que é essencial que existam recursos de qualidade e, principalmente, professores capacitados e em constante formação para que possam atender estes alunos e o projeto Construindo meu Projeto de Vida.

\section{Referências bibliográficas}

POLLAK, Lindsey. Da Escola Para O Mercado De Trabalho: 90 dicas para conseguir um bom emprego. São Paulo, 2008, pág. 47-53.

LEAL, Ruy Livro. Superdicas para o Jovem Escolher Bem Sua Profissão. São Paulo, 2010, pág.48-72.

CASTRO, Robson. Livro Jovens x Mercado de Trabalho. São Paulo, 2008, pág. 2

http://pepsic.bvsalud.org/scielo.php?script=sci_arttext\&pid=S1677-

04712008000100005 Acesso em: 20 março de 2017

http://educarparacrescer.abril.com.br/comportamento/dicas-escolha-profissao472174.shtml Acesso em: 20 março de 2017

http://monografias.brasilescola.uol.com.br/pedagogia/a-importancia-afetividade-narelacao-professor-aluno.htm Acesso em: 21 março de 2017

https://pt.wikipedia.org/wiki/Pedagogo Acesso em: 21 março de 2017

http://www.portalcmc.com.br/eu-nao-sei-o-que-quero-da-vida/\# Acesso em: 22 março de 2017

http://blogpedagogicoruibarbosa.blogspot.com.br/2011/03/perfil-socio-economicocultural-da.html Acesso em: 22 março 2017

https://psicologado.com/atuacao/psicologia-escolar/o-conflito-no-ambienteescolarAcesso em:22 março de 2017

http://www.scielo.br/scielo.php?script=sci_arttext\&pid=S0102-

71822008000300011Acesso em:23 março de 2017

http://www.umc.br/_img/_diversos/servicos/biblioteca/trabalhos_academicos.PDFAcess o em: 23 março de $\overline{2017}$

http://fourstalkers.blogspot.com.br/Acesso em: 24 março de 2017

http://www.sejabixo.com.br/vestibular/como2.asp?id=479Acesso em: 25 março de 2017

http://seuguiaperfeito.com.br/como-montar-uma-justificativa-de-tcc/Acesso: 26 março de 2017

http://blogsaladeaula.blogspot.com.br/2012/01/projeto-pedagogico-e-planoescolar.htmlAcesso em: 27 março de 2017

scielo.wwwbr/pdf/cp/n106/n106a09.pdf Acesso em : 03 abril de 2017

\section{Revista ALTERJOR}

Grupo de Estudos Alterjor: Jornalismo Popular e Alternativo (ECA-USP)

Ano 11 - Volume 02 - Edição 24 - Julho-Dezembro de 2021

Av. Professor Lúcio Martins Rodrigues, 443, Cidade Universitária, São Paulo, CEP: 05508-020 